\title{
Pneumothorax in patients with respiratory failure in ICU
}

\author{
Joseph Thachuthara-George
}

Interventional Pulmonary Program, Division of Pulmonary, Allergy, and Critical Care Medicine, UAB, The University of Alabama at Birmingham, Birmingham, AL, USA

Correspondence to: Joseph Thachuthara-George, MD. Assistant Professor of Medicine, Interventional Pulmonary Program, Division of Pulmonary, Allergy, and Critical Care Medicine, UAB, The University of Alabama at Birmingham, THT 422, 1720 2ND AVE S, Birmingham, AL 35294, USA. Email: jtgeorge@uabmc.edu.

\begin{abstract}
Pneumothorax is not an uncommon occurrence in ICU patients. Barotrauma and iatrogenesis remain the most common causes for pneumothorax in critically ill patients. Patients with underlying lung disease are more prone to develop pneumothorax, especially if they require positive pressure ventilation. A timely diagnosis of pneumothorax is critical as it may evolve into tension physiology. Most occurrences of pneumothoraces are readily diagnosed with a chest X-ray. Tension pneumothorax is a medical emergency, and managed with immediate needle decompression followed by tube thoracostomy. A computed tomography (CT) scan of the chest remains the gold standard for diagnosis; however, getting a CT scan of the chest in a critically ill patient can be challenging. The use of thoracic ultrasound has been emerging and is proven to be superior to chest $\mathrm{X}$-ray in making a diagnosis. The possibility of occult pneumothorax in patients with thoracoabdominal blunt trauma should be kept in mind. Patients with pneumothorax in the ICU should be managed with a tube thoracostomy if they are symptomatic or on mechanical ventilation. The current guidelines recommend a small-bore chest tube as the first line management of pneumothorax. In patients with persistent air leak or whose lungs do not re-expand, a thoracic surgery consultation is recommended. In non-surgical candidates, bronchoscopic interventions or autologous blood patch are other options.
\end{abstract}

Keywords: Pneumothorax; critical care; mechanical ventilation; respiratory failure; barotrauma; ICU

Submitted Nov 19, 2020. Accepted for publication Feb 24, 2021.

doi: $10.21037 /$ jtd-19-3752

View this article at: http://dx.doi.org/10.21037/jtd-19-3752

\section{Introduction}

Pneumothorax is a condition in which air is noted in the pleural space (1). It is classified as spontaneous (primary or secondary), traumatic or iatrogenic. Primary spontaneous pneumothorax occurs in individuals with no clinically apparent lung disease, whereas secondary spontaneous pneumothorax occurs as a complication of preexisting lung disease. Traumatic pneumothorax occurs as a result of penetrating or blunt trauma to the chest wall (2). Iatrogenic pneumothorax occurs as a result of diagnostic and therapeutic intervention and is the most common cause of pneumothorax in the ICU setting $(2,3)$. Incidence in the 1990s was up to $24 \%$, but more recent data show that the incidence has come down to about $3 \%(4,5)$. This is likely from a change in medical management of ICU patients over time (6). Pneumothorax can be misdiagnosed at initial presentation in about $32 \%$ of patients admitted to the ICU (7). It has a mortality rate of $68 \%$, with the worst prognosis being in patients with septic shock and barotrauma (3).

\section{Etiology and risk factors}

Air can enter the pleural space by three routes: (I) communication between alveoli and pleura, (II) communication (direct or indirect) between atmosphere and pleural space, and (III) presence of gas producing organisms in the pleural space (1). Pneumothorax in the ICU occurs mostly as a result of barotrauma as well as various invasive procedures. A study by de Lassence $e t$ al. shows that about 
Table 1 Etiology of pneumothorax in the $\operatorname{ICU}(5,12)$
(I) Underlying lung disease:
a. ARDS
b. Pneumonia
c. COPD/emphysema
(II) Trauma
(III) Invasive interventions
d. Positive pressure ventilation
e. Central venous line insertion
f. Bronchoscopy
g. Surgical procedures involving thorax, head and neck
h. Abdominal procedures

(I) Underlying parenchymal lung disease predispose patients to develop pneumothorax. (II) Post trauma patients are at risk for developing pneumothorax. (III) latrogenic pneumothorax can be caused due to various invasive diagnostic and therapeutic interventions.

$55 \%$ of the pneumothoraces in the ICU were from invasive procedures and the rest from barotrauma (5). Invasive procedures that commonly cause pneumothorax in the ICU include thoracentesis, central venous line insertion, and bronchoscopy with biopsy (3). There are a variety of risk factors that may predispose a patient to develop pneumothorax. There is strong evidence to suggest that patients with underlying lung disease, specifically acute respiratory distress syndrome (ARDS), are more prone to develop pneumothorax $(5,8)$. Papazian et al. demonstrate significant decrease in pneumothorax occurrence in patients with severe ARDS who were started on muscle relaxants within $48 \mathrm{~h}$ of disease onset (9). Implementation of lung protective ventilation has resulted in a significant decrease in pneumothorax incidence when compared to the pre lung protective ventilation era (6). Other risk factors include adult immunodeficiency, cardiogenic pulmonary edema and body weight less than $80 \mathrm{~kg}$ (5). Traumatic pneumothorax is also seen in ICUs with trauma patients. Pneumothorax can occur in about $35 \%$ of patients with thoracic injuries, and of these about $22 \%$ of the pneumothoraces can be occult $(10,11)$. Common causes for pneumothorax in the ICU are listed in Table 1.

\section{Diagnosis of pneumothorax}

Timely diagnosis of pneumothorax in critically ill patients is paramount given the high mortality risk (3). Diagnosis of pneumothorax starts with history and physical examination. In a critically ill patient, change in respiratory status with new or worsening hypoxia, tachycardia, hypotension, decreased breath sounds on the affected side, tracheal deviation away from the affected side, surgical emphysema, decrease in tidal volume with pressure controlled ventilation or increase in airway pressures (peak and plateau), with volume controlled ventilation may be a sign of pneumothorax. However, these signs are nonspecific and can be related to other disease conditions. For example, airway pressures may be elevated from obstruction of the endotracheal tube and diminished breath sounds may be due to underlying lung disease such as COPD or from atelectasis (12). As such, clinicians should maintain a high index of suspicion and given the variability of these signs and symptoms, a chest X-ray is usually needed to confirm the diagnosis (13). However, respiratory and hemodynamic signs of tension pneumothorax should be considered a medical emergency and addressed immediately, as this requires urgent needle decompression (12).

\section{Thoracic ultrasonography}

Ultrasonography in diagnosis of pneumothorax was first described in a horse by Rantanen in 1986 (14). Thoracic ultrasound use has been rapidly expanding and becoming an essential part of ICU care and emergency medicine (15). Point-of-care ultrasound is easy to use, readily available in most ICUs, efficient, reliable, and cost effective, with the added advantage of real time imaging. It also has the advantage of safety, as it does not expose the patient to radiation like a chest $\mathrm{X}$-ray or $\mathrm{CT}$ scan. Since these exams can be done at bedside, they avoid the risks associated with transporting a critically ill patient (16). On thoracic ultrasound, pleura appears as a highly echogenic band which moves with respiration and is referred to as the gliding sign or lung sliding (Video 1) (17). In their study of critically ill patients, Lichtenstein et al. demonstrate the absence of lung sliding to have $95 \%$ sensitivity and $91 \%$ specificity, with a negative predictive value of $100 \%$. This means that the presence of lung sliding can rule out pneumothorax at the area being examined (18). An alternative mode named the M-Mode (motion mode) has also been used as an adjunct to detect pneumothorax. There are two different types of images obtained: the "stratosphere sign" or "barcode sign" (Figure 1), which represents absent pleural motion, and the "sandy beach" or "seashore sign" (Figure 2) which 
represents pleural motion. Use of $M$ mode along with conventional B mode has been shown to increase the diagnostic yield of lung sliding, especially in early users (19). In 2000, Lichtenstein et al. introduced the concept of the "lung point" sign (Video 2). This is the point where the pneumothorax pattern noted on a sonogram is replaced by the fleeting appearance of lung pattern. This has an overall sensitivity of $66 \%$ with increased sensitivity (75\%) in occult pneumothorax and has a specificity of $100 \%$ (20). Another helpful sign on thoracic ultrasonography is the "comettail artifacts," also known as B Lines (Figure 3), which are vertical ultrasound artifacts arising from the lung-wall interface that rule out a complete pneumothorax (21). The absence of lung sliding is suggestive of pneumothorax, but it is not specific for diagnosis. This is because it can be seen in other conditions such as atelectasis, especially related to selective intubation, conditions that causes adherence of pleura to the chest wall, jet ventilation, esophageal intubations and apnea (22). "Lung pulse" is described as the perception of heart activity at the pleural line, which, along with absent pleural sliding, represents atelectasis (23).

There have been multiple studies comparing the diagnostic yield of ultrasonography to chest radiography in diagnosing pneumothorax. A meta-analysis by Alrajab et al. showed a pooled sensitivity of 78.6\% (95\% CI, 68.1 to 98.1) and a specificity of $98.4 \%$ (95\% CI, 97.3 to 99.5 ) for ultrasonography. Chest radiography had a pooled sensitivity of $39.8 \%$ (95\% CI, 29.4 to 50.3 ) and a specificity of $99.3 \%$ (95\% CI, 98.4 to 100 ), suggesting chest ultrasonography to be more accurate in detecting pneumothorax when compared to chest radiography (24). Thoracic ultrasound has also been noted to be helpful in detecting occult pneumothorax. A study done by Soldati et al. comparing ultrasonography to CT scan and chest radiography in diagnosing occult pneumothorax showed $92 \%$ diagnostic yield with thoracic ultrasound when compared to $52 \%$ diagnostic yield with chest radiograph and when compared with CT in which all the patients were noted to have pneumothorax (25). The learning curve for chest ultrasound is relatively short, and it can be a useful tool in the ICU to look for pneumothorax after central venous line placement $(26,27)$.

\section{Chest radiograph}

Critically ill patients are often supine or semi-recumbent. This poses a challenge to interpreting chest radiography. A study by Tocino et al. in critically ill patients noted that
$30 \%$ of the pneumothoraces were initially missed on chest radiograph. This was mostly due to the involvement of anteromedial and subpulmonic pleural recess in about $64 \%$ of the patients (28). On a supine radiograph, pneumothorax may be seen as air present in the deep lateral costophrenic angle known as the deep sulcus sign (Figure 4) (29). Expiratory chest radiographs were assumed to enhance the diagnostic yield of small apical pneumothoraces. However, it was found to have no increase in diagnostic yield and is not recommended based on current guidelines $(30,31)$. Select situations, such as presence of skin folds, emphysematous bullae, and visceral gas within the chest may mimic a pneumothorax on a chest radiograph. If chest $\mathrm{X}$-ray findings do not correlate clinically, then a CT may be considered prior to acting on the radiograph findings (12).

In critically ill patients with abnormal lung disease from pneumonia, ARDS or interstitial lung disease, diagnosis of pneumothorax on routine chest radiograph may be challenging. In these conditions, the lung may not collapse because of parenchymal stiffness or pleural adhesions. This leads to development of small loculated pneumothoraces, which can later develop into tension pneumothorax $(28,32)$.

\section{Computed tomography}

Patients with respiratory failure in the ICU, especially in the medical ICU, often have underlying lung disease that makes it difficult for a diagnosis of pneumothorax to be made based on a chest radiograph. Chest X-rays in patients with complex cystic lung disease may be difficult to interpret and can mask pneumothorax. These conditions can also cause lung adherence to the chest wall, resulting in loculated pneumothorax, which can be difficult to detect on chest radiograph (33). As previously mentioned, pneumothorax can be localized in the pleural recesses, causing it to be missed initially in about $30 \%$ of the patients on initial chest radiograph with a risk of it progressing to tension pneumothorax (28). CT scan has been shown to be superior to chest radiograph in diagnosing and sizing of pneumothorax; hence, it is considered the gold standard test for evaluating pneumothorax (34).

The use of CT scan has led to a better understanding of thoracic anatomy. This has also led to an increase in diagnosis of pneumothoraces, which were initially not recognized clinically or on chest radiographs. These are called occult pneumothoraces (35). The incidence of occult pneumothorax ranges between $1.8-4 \%(36,37)$. In patients with occult pneumothorax, especially in patients 


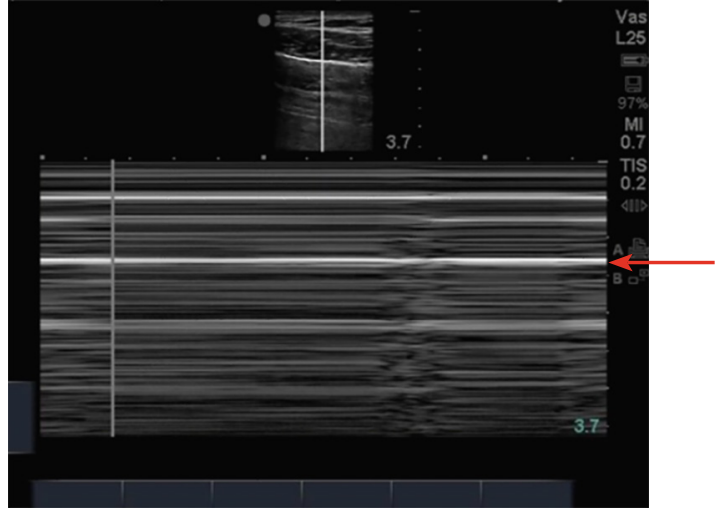

Figure 1 Barcode sign. M-Mode image demonstrates a linear and laminar pattern above the bright pleural line (arrow) corresponding to superficial tissue and an identical pattern noted below the pleural line. This sign known as "barcode sign" or "stratosphere sign" indicates absence of lung sliding and possibility of pneumothorax at this point of exam. Note that the presence of this sign is suggestive of but not confirmatory for pneumothorax.

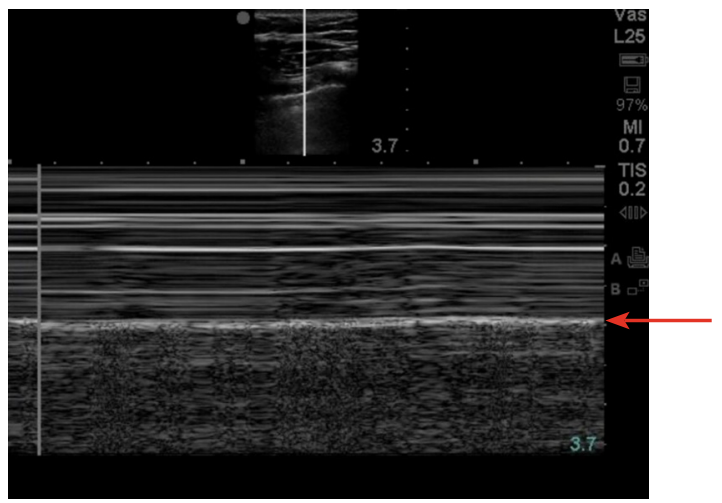

Figure 2 Sea shore Sign. M-Mode image shows a bright pleural line (arrow) with a linear and laminar pattern above the line corresponding to superficial tissue and a granular pattern seen below the pleural line. This sign known as "Sea Shore" sign indicates normal lung sliding and rules out pneumothorax.

receiving mechanical ventilation, there is a concern for worsening of pneumothorax and potential development of tension pneumothorax. Retrospective studies done in the past have shown conservative management to be a safer option in patients with occult pneumothoraces (38). In their prospective multicenter randomized controlled trial, Kirkpatrick et al. demonstrated that occult pneumothorax can be safely observed in patients receiving mechanical

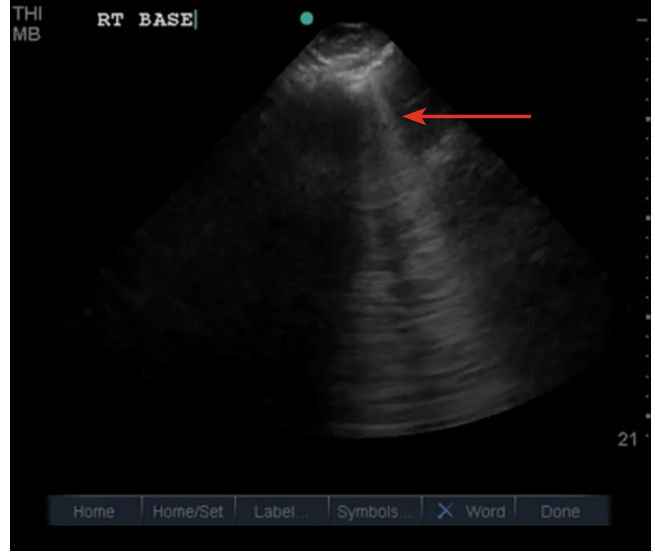

Figure 3 Comet Tail SignComet tail sign or artifacts also known as B-lines are hyperechoic reverberations originating from the visceral pleura and travel almost perpendicular to the pleural line. These are lost when air accumulates in the pleural space which prevents propagation of ultrasound waves. Presence of comet-tail sign rules out pneumothorax.

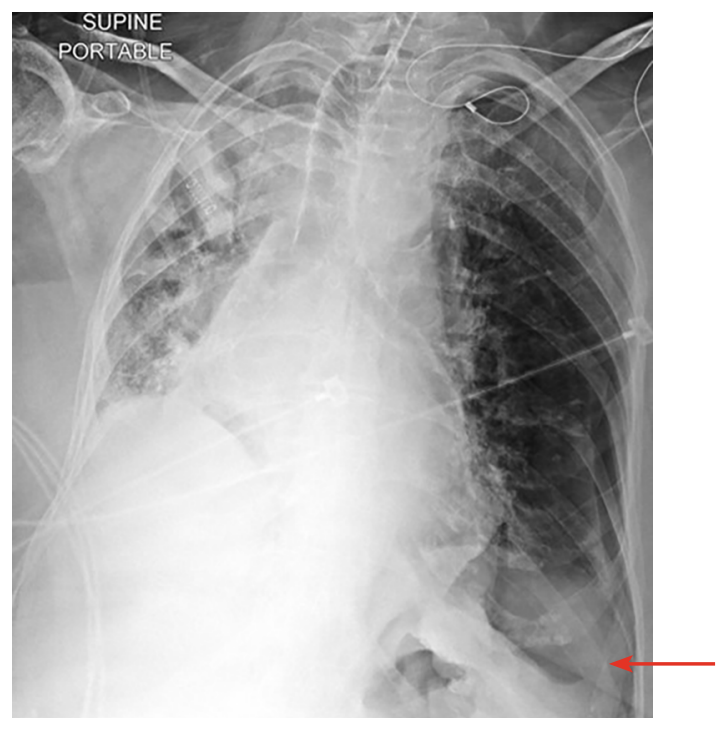

Figure 4 Deep sulcus sign on left side. Deep sulcus sign noted on this chest $\mathrm{X}$-ray shows a deep radiolucent area at the left lateral costophrenic angle (arrow).

ventilation. However, those requiring mechanical ventilation for more than a week had an increased requirement of pleural drainage tube. In the pleural drainage group, $15 \%$ experienced complications related to the procedure (39). The possibility of occult pneumothorax should be kept in mind for patients with a history of blunt trauma. 


\section{Management of pneumothorax}

Management of pneumothorax in critically ill patients depends on the cause as well as the underlying clinical condition (40). The rate of resolution of spontaneous pneumothorax is around $1.25-2.2 \%$ per 24 hours if it is managed conservatively without pleural drainage (31). However, ICU patients often have poor pulmonary reserve, and even a small pneumothorax can cause a significant cardiopulmonary effect (41). Pneumothorax secondary to barotrauma, tension pneumothorax and concurrent septic shock are all significant independent risk factors for mortality in critically ill patients (3). British Thoracic Society (BTS) guidelines recommend chest drain insertion for any patients on mechanical ventilation, with tension pneumothorax after initial needle decompression, traumatic hemopneumothorax and post-surgical pneumothorax (42). Hence, many of the critically ill patients will end up needing chest drainage tube either because of the underlying cause or because of their poor reserve requiring the pneumothorax to be drained even if it is small. There are various management options available based on the severity of symptoms, size of pneumothorax and persistence of bronchopleural fistula (Figure 5).

\section{Emergent needle decompression}

Tension pneumothorax is a medical emergency in which there is expanding air volume within the chest cavity with clinical signs and symptoms of progressive hypoxemia, tachycardia, respiratory distress and hypotension, and requires rapid decompression of air from the chest cavity (43). Presentation can be more pronounced, and progression can be rapid in mechanically ventilated patients when compared to those breathing unassisted (44). Hence, it is important to make a timely diagnosis of tension pneumothorax and intervene immediately. In critically ill patients, the diagnosis often needs to be made clinically, as there is not enough time to get a chest radiograph for confirmation. Chest ultrasound can be helpful if readily available, but intervention should not be delayed if there is high clinical suspicion for tension pneumothorax $(31,45)$. Tension pneumothorax should be suspected when respiratory or cardiovascular decompensation is noted in patients who received cardiopulmonary resuscitation (CPR) or have a chest tube that is blocked (45). Needle decompression is done in the second or third intercostal space (ICS) in the mid-clavicular line using a standard 14 gauge $(4.5 \mathrm{~cm})$ cannula until an audible rush of air is appreciated (46). However, in up to $35 \%$ of patients, a standard $4.5 \mathrm{~cm}$ canula may not be long enough to penetrate the chest wall, leading to treatment failure (47). This can be avoided by using a trocar $(7 \mathrm{~cm})$ or use of 4th or 5 th ICS in the mid-axillary line, as it contains less fat and muscle mass. However, this area does carry the risk of lung injury in supine patients (46). A chest drain placement should be performed after canula decompression, and the canula should be left in place until air bubbles are noted in the water seal to confirm correct placement of the chest drain (31).

\section{Chest drain placement}

There are a wide variety of chest tubes available, both small-bore (10-14 Fr) and large bore (>20 Fr). In the past, large bore chest tubes were placed for treatment of pneumothorax. However, in the last decade or so, small bore chest tubes, which are placed using the modified Seldinger technique, have become more common in managing pneumothorax. These small-bore chest tubes are easier to place and cause less pain at the insertion site. Small-bore chest tubes are associated with lower complication rates, with injury occurring in $0.2 \%$ and malposition occurring in $0.6 \%$, as compared to large-bore chest tubes, where the injury occurs in about $1.4 \%$ and malposition occurs in about $6.5 \%$. The current BTS guidelines recommend the use of small-bore chest tube as first line therapy for management of pneumothorax (42). In their retrospective review, Liu et al. demonstrated no significant difference between the evacuation rates of large bore and small-bore chest tubes (48).

\section{Persistent air leak}

If the air leak lasts more than 5-7 days, then it is called persistent air leak (49). In the era prior to lung protective ventilation, there was significantly high incidence of persistent air leak in patients who developed pneumothorax while on a mechanical ventilator (50). The overall incidence of pneumothorax has decreased with implementation of a lung protective ventilation strategy (5). However, patients with underlying lung disease are at risk for developing persistent air leak (49). Initial management is often conservative, and it can be effective if enough time is given for the alveolar-pleural or broncho-pleural fistula to close (51). The 2001 American College of Chest Physicians consensus statement on management of spontaneous pneumothorax recommends thoracic surgery consultation if the air leak persists after four days (52). The BTS guidelines 


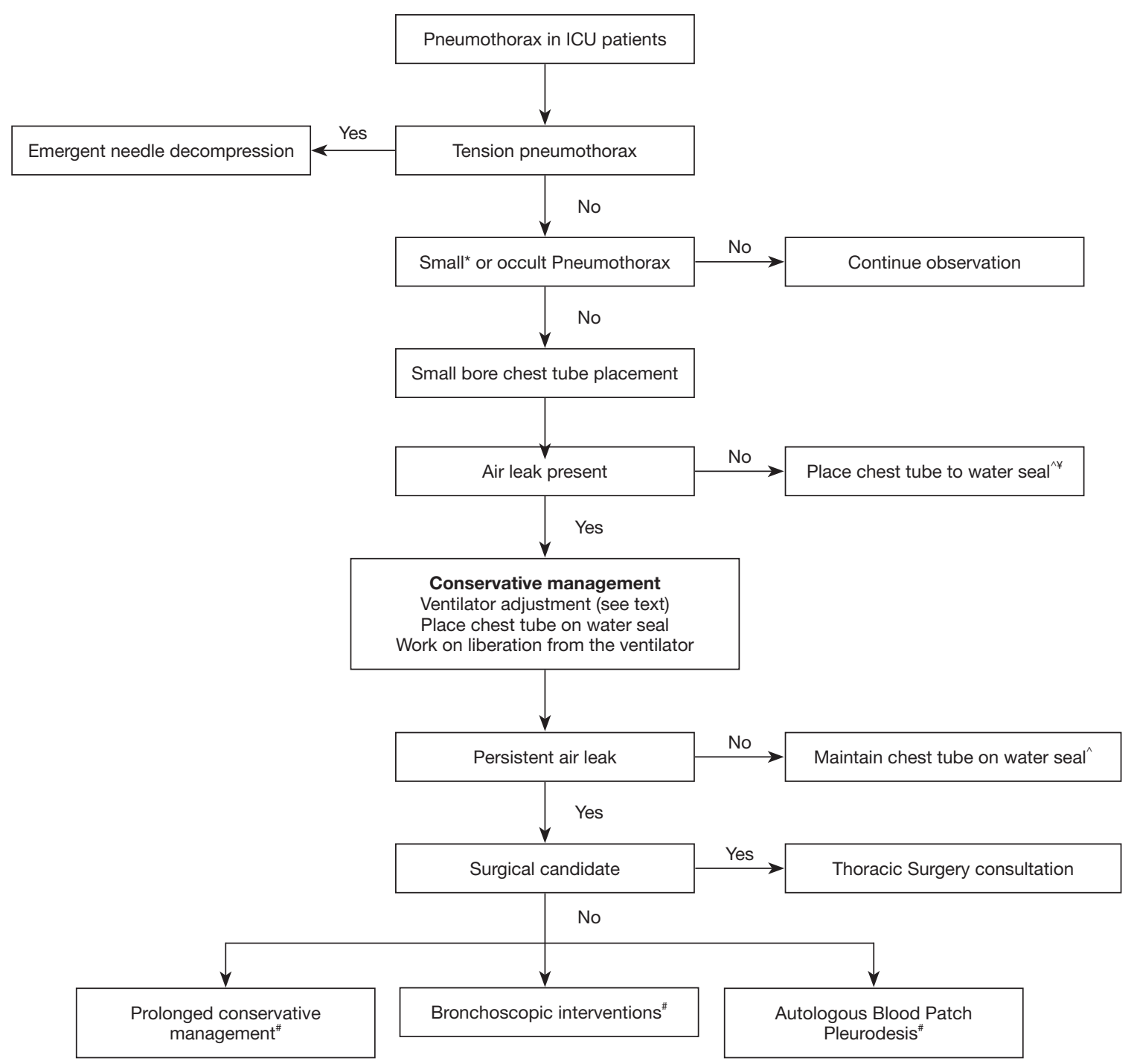

Figure 5 Algorithm for management of pneumothorax in ICU. *, based on the guidelines followed; ${ }^{\text {, }}$, decision on when to remove the chest tube should be made by the treating physician; ${ }^{*}$, if lung has re-expanded; ${ }^{*}$, any of the three non-surgical interventions can be performed based on the clinical condition.

recommend thoracic surgery consultation if the air leak persists for 3-5 days (31). In patients who are not a surgical candidate, non-surgical methods such as bronchoscopic interventions as well as blood patch may be considered (49). However, guidelines are lacking for non-surgical management of persistent air leak.

\section{Conservative management}

Persistent air leak can be challenging to manage when the patient is receiving mechanical ventilation. In such situations, the strategy should focus on lowering the peak airway pressure by reducing the tidal volume and end-expiratory pressure as well as use of pressure-cycled ventilation $(49,53)$. Placing the chest tube on water seal from suction has also shown to help stop the air leak (54).

\section{Thoracic surgery consult}

Surgical pleurodesis remains the most effective method for treating recurrent or persistent pneumothorax. Open thoracotomy with partial pleurectomy remains 
the best modality, and pleurodesis with Video Assisted Thoracoscopic Surgery (VATS) also has comparable results. These results are based on patients undergoing surgical pleurodesis for spontaneous or secondary spontaneous pneumothorax $(55,56)$. The American College of Chest Physicians consensus statement recommends pleurodesis with VATS (52). Critically ill patients may not be a surgical candidate, and there is little data or guidelines to support further clinical decision making in this patient population. If the patient is not a surgical candidate, then prolonged conservative management can be tried, such as placing the chest tube to water seal as well as adjusting the ventilator settings as mentioned earlier $(53,57)$. If conservative management fails in these patients, then other available options are either bronchoscopic management or autologous blood patch pleurodesis and are discussed below.

\section{Bronchoscopic management of persistent air leak}

Various bronchoscopic methods have been tried in patients with persistent air leak with variable success, and all of them have been anecdotal. These include fibrin sealants, metal coils, Watanabe spigots, and alcohol sclerosis, all reported as case reports and series (49). At present, Spiration intra bronchial valve (IBV) system is the only device approved by the FDA for bronchoscopic treatment of persistent air leak. These are one-way valves placed with a flexible bronchoscope into the segmental or subsegmental airways. This limits airflow into the distal airways while allowing secretions and air to move proximally. There are two endobronchial valves (EBV) available in the market: Zephyr valve by PulmonX Inc. and the Spiration Valve System by Olympus (49). In 2009, Travaline et al. reported the use of EBV in 40 patients with persistent air leak, with complete resolution in $47.5 \%$ and reduction in air leak in $45 \%$. The mean time for chest tube removal was 21 days. Of the forty patients, only six patients experienced adverse events such as valve expectoration, moderate oxygen desaturation, valve mispositioning requiring redeployment and methicillinresistant staphylococcus aureus colonization (58). Gillespie et al. published their experience with valves in eight patients, where $57 \%$ of patients were discharged within $2-3$ days (59). In their case series, Mahajan et al. reported the safety and effectiveness of IBV in ICU patients with prolonged air leak requiring high levels of supplemental oxygen or mechanical ventilation (60). Reed et al. reported the used of EBV in post-surgical patients as well as in patients with cavitary lung disease. Their series noted the successful removal of chest tube in all patients who survived the clinical course (61).

\section{Autologous blood patch pleurodesis}

Autologous Blood Patch Pleurodesis (ABPP) was first reported by Robinson in 1987, when 25 patients with fully expanded lungs but prolonged air leak underwent instillation of $50 \mathrm{~mL}$ of autologous blood anywhere between one to three times. The procedure was successful in $85 \%$ of the patients (62). ABPP is performed by injecting $50-100 \mathrm{~mL}$ autologous blood through the chest tube followed by flushing the chest tube with $10 \mathrm{~mL}$ of saline and clamping for about $30 \mathrm{~min}$, followed by placing it back on the water seal (63). If the chest tube cannot be clamped, it can be hooked over a drip stand for the air to escape in order to prevent tension physiology $(49,64)$. A review of ten published studies showed blood pleurodesis to be superior to conservative management with optimal volume of $100 \mathrm{~mL}$. Patients undergoing blood pleurodesis were noted to have an overall success rate of $92.7 \%$, with a shorter time to achieve pleurodesis (65). The reported complications are rare but may include fever, empyema, pleuritis and blood clot blocking the chest tube causing tension physiology $(49,64)$.

\section{Conclusions}

Pneumothorax in critically ill patients, whether small or large, may have a significant clinical impact. A timely diagnosis and intervention of this condition is crucial in ICU patients. In critically ill patients, the use of point-ofcare ultrasound plays a key role in prompt recognition and management of pneumothorax. Patients on mechanical ventilation often need tube thoracostomy, given their risk of developing tension pneumothorax. Tension pneumothorax is a medical emergency, and diagnosis is usually based on clinical signs and symptoms. Trauma patients with occult pneumothorax may be managed with clinical observation based on the clinical status. Small bore chest tubes are recommended for the initial management of pneumothorax. Guidelines recommend thoracic surgery consultation for patients with prolonged air leak. In non-surgical candidates, alternative treatments with bronchoscopic intervention and autologous blood patch pleurodesis may be considered. 


\section{Acknowledgments}

I would like to thank Dr. Pralay Sarkar for providing the chest ultrasound pictures.

Funding: None.

\section{Footnote}

Provenance and Peer Review: This article was commissioned by the Guest Editors (Jonathan S. Kurman, Ashutosh Sachdeva and Rahul Nanchal) for the series "Interventional Pulmonology in the Intensive Care Unit Environment" published in fournal of Thoracic Disease. The article has undergone the external peer review.

Conflicts of Interest: The author has completed the ICMJE uniform disclosure form (available at: http://dx.doi. org/10.21037/jtd-19-3752). The series "Interventional Pulmonology in the Intensive Care Unit Environment" was commissioned by the editorial office without any funding or sponsorship. The author has no other conflicts of interest to declare.

Ethical Statement: The author is accountable for all aspects of the work in ensuring that questions related to the accuracy or integrity of any part of the work are appropriately investigated and resolved.

Open Access Statement: This is an Open Access article distributed in accordance with the Creative Commons Attribution-NonCommercial-NoDerivs 4.0 International License (CC BY-NC-ND 4.0), which permits the noncommercial replication and distribution of the article with the strict proviso that no changes or edits are made and the original work is properly cited (including links to both the formal publication through the relevant DOI and the license). See: https://creativecommons.org/licenses/by-nc-nd/4.0/.

\section{References}

1. Noppen M, De Keukeleire T. Pneumothorax. Respiration 2008;76:121-7.

2. Sahn SA, Heffner JE. Spontaneous pneumothorax. N Engl J Med 2000;342:868-74.

3. Chen KY, Jerng JS, Liao WY, et al. Pneumothorax in the ICU: patient outcomes and prognostic factors. Chest 2002;122:678-83.

4. Gammon RB, Shin MS, Buchalter SE. Pulmonary barotrauma in mechanical ventilation. Patterns and risk factors. Chest 1992;102:568-72.

5. de Lassence A, Timsit JF, Tafflet M, et al. Pneumothorax in the intensive care unit: incidence, risk factors, and outcome. Anesthesiology 2006;104:5-13.

6. Miller MP, Sagy M. Pressure characteristics of mechanical ventilation and incidence of pneumothorax before and after the implementation of protective lung strategies in the management of pediatric patients with severe ARDS. Chest 2008;134:969-73.

7. Kollef MH. Risk factors for the misdiagnosis of pneumothorax in the intensive care unit. Crit Care Med 1991;19:906-10.

8. Gammon RB, Shin MS, Groves RH, Jr., et al. Clinical risk factors for pulmonary barotrauma: a multivariate analysis. Am J Respir Crit Care Med 1995;152:1235-40.

9. Papazian L, Forel JM, Gacouin A, et al. Neuromuscular blockers in early acute respiratory distress syndrome. $\mathrm{N}$ Engl J Med 2010;363:1107-16.

10. Kulshrestha P, Munshi I, Wait R. Profile of chest trauma in a level I trauma center. J Trauma 2004;57:576-81.

11. Wilson H, Ellsmere J, Tallon J, et al. Occult pneumothorax in the blunt trauma patient: tube thoracostomy or observation? Injury 2009;40:928-31.

12. Rankine JJ, Thomas AN, Fluechter D. Diagnosis of pneumothorax in critically ill adults. Postgrad Med J 2000;76:399-404.

13. Tschopp JM, Bintcliffe O, Astoul P, et al. ERS task force statement: diagnosis and treatment of primary spontaneous pneumothorax. Eur Respir J 2015;46:321-35.

14. Rantanen NW. Diseases of the thorax. Vet Clin North Am Equine Pract 1986;2:49-66.

15. Liccardo B, Martone F, Trambaiolo P, et al. Incremental value of thoracic ultrasound in intensive care units: Indications, uses, and applications. World J Radiol 2016;8:460-71.

16. Mayo PH, Copetti R, Feller-Kopman D, et al. Thoracic ultrasonography: a narrative review. Intensive Care Med 2019;45:1200-11.

17. Mathis G. Thoraxsonography--Part I: Chest wall and pleura. Ultrasound Med Biol 1997;23:1131-9.

18. Lichtenstein DA, Menu Y. A bedside ultrasound sign ruling out pneumothorax in the critically ill. Lung sliding. Chest 1995;108:1345-8.

19. Avila J, Smith B, Mead T, et al. Does the Addition of M-Mode to B-Mode Ultrasound Increase the Accuracy of Identification of Lung Sliding in Traumatic Pneumothoraces? J Ultrasound Med 2018;37:2681-7. 
20. Lichtenstein D, Meziere G, Biderman P, et al. The "lung point": an ultrasound sign specific to pneumothorax. Intensive Care Med 2000;26:1434-40.

21. Lichtenstein D, Meziere G, Biderman P, et al. The comettail artifact: an ultrasound sign ruling out pneumothorax. Intensive Care Med 1999;25:383-8.

22. Lichtenstein DA. Lung ultrasound in the critically ill. Ann Intensive Care 2014;4:1.

23. Lichtenstein DA, Lascols N, Prin S, et al. The "lung pulse": an early ultrasound sign of complete atelectasis. Intensive Care Med 2003;29:2187-92.

24. Alrajab S, Youssef AM, Akkus NI, et al. Pleural ultrasonography versus chest radiography for the diagnosis of pneumothorax: review of the literature and metaanalysis. Crit Care 2013;17:R208.

25. Soldati G, Testa A, Sher S, et al. Occult traumatic pneumothorax: diagnostic accuracy of lung ultrasonography in the emergency department. Chest 2008;133:204-11.

26. Abbasi S, Farsi D, Hafezimoghadam P, et al. Accuracy of emergency physician-performed ultrasound in detecting traumatic pneumothorax after a 2-h training course. Eur J Emerg Med 2013;20:173-7.

27. Vezzani A, Brusasco C, Palermo S, et al. Ultrasound localization of central vein catheter and detection of postprocedural pneumothorax: an alternative to chest radiography. Crit Care Med 2010;38:533-8.

28. Tocino IM, Miller MH, Fairfax WR. Distribution of pneumothorax in the supine and semirecumbent critically ill adult. AJR Am J Roentgenol 1985;144:901-5.

29. Gordon R. The deep sulcus sign. Radiology 1980;136:25-7.

30. Schramel FM, Golding RP, Haakman CD, et al. Expiratory chest radiographs do not improve visibility of small apical pneumothoraces by enhanced contrast. Eur Respir J 1996;9:406-9.

31. MacDuff A, Arnold A, Harvey J, et al. Management of spontaneous pneumothorax: British Thoracic Society Pleural Disease Guideline 2010. Thorax 2010;65 Suppl 2:ii18-31.

32. Boland GW, Lee MJ, Sutcliffe NP, et al. Loculated pneumothoraces in patients with acute respiratory disease treated with mechanical ventilation: preliminary observations after image-guided drainage. J Vasc Interv Radiol 1996;7:247-52.

33. Phillips GD, Trotman-Dickenson B, Hodson ME, et al. Role of CT in the management of pneumothorax in patients with complex cystic lung disease. Chest
1997;112:275-8.

34. Kelly AM, Weldon D, Tsang AY, et al. Comparison between two methods for estimating pneumothorax size from chest X-rays. Respir Med 2006;100:1356-9.

35. Wall SD, Federle MP, Jeffrey RB, et al. CT diagnosis of unsuspected pneumothorax after blunt abdominal trauma. AJR Am J Roentgenol 1983;141:919-21.

36. de Moya MA, Seaver C, Spaniolas K, et al. Occult pneumothorax in trauma patients: development of an objective scoring system. J Trauma 2007;63:13-7.

37. Misthos P, Kakaris S, Sepsas E, et al. A prospective analysis of occult pneumothorax, delayed pneumothorax and delayed hemothorax after minor blunt thoracic trauma. Eur J Cardiothorac Surg 2004;25:859-64.

38. Zhang M, Teo LT, Goh MH, et al. Occult pneumothorax in blunt trauma: is there a need for tube thoracostomy? Eur J Trauma Emerg Surg 2016;42:785-90.

39. Kirkpatrick AW, Rizoli S, Ouellet JF, et al. Occult pneumothoraces in critical care: a prospective multicenter randomized controlled trial of pleural drainage for mechanically ventilated trauma patients with occult pneumothoraces. J Trauma Acute Care Surg 2013;74:74754; discussion 754-5.

40. Rahman NM, Davies RJ, Gleeson FV. Pleural interventions: management of acute and chronic pneumothorax. Semin Respir Crit Care Med 2008;29:427-40.

41. Hsu CW, Sun SF. Iatrogenic pneumothorax related to mechanical ventilation. World J Crit Care Med 2014;3:8-14.

42. Havelock T, Teoh R, Laws D, et al. Pleural procedures and thoracic ultrasound: British Thoracic Society Pleural Disease Guideline 2010. Thorax 2010;65 Suppl 2:ii61-76.

43. Barton ED. Tension pneumothorax. Curr Opin Pulm Med 1999;5:269-74.

44. Roberts DJ, Leigh-Smith S, Faris PD, et al. Clinical Presentation of Patients With Tension Pneumothorax: A Systematic Review. Ann Surg 2015;261:1068-78.

45. Yarmus L, Feller-Kopman D. Pneumothorax in the critically ill patient. Chest 2012;141:1098-105.

46. Leigh-Smith S, Harris T. Tension pneumothorax--time for a re-think? Emerg Med J 2005;22:8-16.

47. Zengerink I, Brink PR, Laupland KB, et al. Needle thoracostomy in the treatment of a tension pneumothorax in trauma patients: what size needle? J Trauma 2008;64:111-4.

48. Liu CM, Hang LW, Chen WK, et al. Pigtail tube drainage in the treatment of spontaneous pneumothorax. Am J 
Emerg Med 2003;21:241-4.

49. Dugan KC, Laxmanan B, Murgu S, et al. Management of Persistent Air Leaks. Chest 2017;152:417-23.

50. Pierson DJ, Horton CA, Bates PW. Persistent bronchopleural air leak during mechanical ventilation. A review of 39 cases. Chest 1986;90:321-3.

51. Chee CB, Abisheganaden J, Yeo JK, et al. Persistent airleak in spontaneous pneumothorax--clinical course and outcome. Respir Med 1998;92:757-61.

52. Baumann MH, Strange C, Heffner JE, et al. Management of spontaneous pneumothorax: an American College of Chest Physicians Delphi consensus statement. Chest 2001;119:590-602.

53. Cho MH, Malhotra A, Donahue DM, et al. Mechanical ventilation and air leaks after lung biopsy for acute respiratory distress syndrome. Ann Thorac Surg 2006;82:261-6.

54. Cerfolio RJ, Bass C, Katholi CR. Prospective randomized trial compares suction versus water seal for air leaks. Ann Thorac Surg 2001;71:1613-7.

55. Thomas P, Le Mee F, Le Hors H, et al. [Results of surgical treatment of persistent or recurrent pneumothorax]. Ann Chir 1993;47:136-40.

56. Hatz RA, Kaps MF, Meimarakis G, et al. Long-term results after video-assisted thoracoscopic surgery for firsttime and recurrent spontaneous pneumothorax. Ann Thorac Surg 2000;70:253-7.

57. Wood DE, Cerfolio RJ, Gonzalez X, et al. Bronchoscopic management of prolonged air leak. Clin Chest Med

Cite this article as: Thachuthara-George J. Pneumothorax in patients with respiratory failure in ICU. J Thorac Dis 2021;13(8):5195-5204. doi: 10.21037/jtd-19-3752
2010;31:127-33, Table of Contents.

58. Travaline JM, McKenna RJ, Jr., De Giacomo T, et al. Treatment of persistent pulmonary air leaks using endobronchial valves. Chest 2009;136:355-60.

59. Gillespie CT, Sterman DH, Cerfolio RJ, et al. Endobronchial valve treatment for prolonged air leaks of the lung: a case series. Ann Thorac Surg 2011;91:270-3.

60. Mahajan AK, Verhoef P, Patel SB, et al. Intrabronchial valves: a case series describing a minimally invasive approach to bronchopleural fistulas in medical intensive care unit patients. J Bronchology Interv Pulmonol 2012;19:137-41.

61. Reed MF, Gilbert CR, Taylor MD, et al. Endobronchial Valves for Challenging Air Leaks. Ann Thorac Surg 2015;100:1181-6.

62. Robinson CL. Autologous blood for pleurodesis in recurrent and chronic spontaneous pneumothorax. Can J Surg 1987;30:428-9.

63. Lang-Lazdunski L, Coonar AS. A prospective study of autologous 'blood patch' pleurodesis for persistent air leak after pulmonary resection. Eur J Cardiothorac Surg 2004;26:897-900.

64. Manley K, Coonar A, Wells F, et al. Blood patch for persistent air leak: a review of the current literature. Curr Opin Pulm Med 2012;18:333-8.

65. Chambers A, Routledge T, Bille A, et al. Is blood pleurodesis effective for determining the cessation of persistent air leak? Interact Cardiovasc Thorac Surg 2010;11:468-72. 